Drug synergy of combinatory treatment with remdesivir and the repurposed drugs fluoxetine and itraconazole effectively impairs SARS-CoV-2 infection in vitro

\title{
Schloer, Sebastian
}

2021-06

Schloer , S, Brunotte , L, Mecate-Zambrano , A, Zheng , S, Tang , J , Ludwig , S \& Rescher , U 2021, ' Drug synergy of combinatory treatment with remdesivir and the repurposed drugs fluoxetine and itraconazole effectively impairs SARS-CoV-2 infection in vitro ' , British Journal of Pharmacology , vol. 178 , no. 11 , pp. 2339-2350 . https://doi.org/10.1111/bph.15418

http://hdl.handle.net/10138/330907

https://doi.org/10.1111/bph.15418

cc_by_nc_nd

publishedVersion

Downloaded from Helda, University of Helsinki institutional repository.

This is an electronic reprint of the original article.

This reprint may differ from the original in pagination and typographic detail.

Please cite the original version. 


\title{
Drug synergy of combinatory treatment with remdesivir and the repurposed drugs fluoxetine and itraconazole effectively impairs SARS-CoV-2 infection in vitro
}

\author{
Sebastian Schloer $^{1}$ | Linda Brunotte ${ }^{2}$ () | Angeles Mecate-Zambrano ${ }^{2}$ \\ Shuyu Zheng ${ }^{3}$ | Jing Tang ${ }^{3}$ (i) | Stephan Ludwig ${ }^{2}$ () | Ursula Rescher ${ }^{1}$ ()
}

${ }^{1}$ Institute of Medical Biochemistry, Center for Molecular Biology of Inflammation, and "Cells in Motion" Interfaculty Centre, University of Muenster, Muenster, Germany

${ }^{2}$ Institute of Virology, Center for Molecular Biology of Inflammation, and "Cells in Motion" Interfaculty Centre, University of Muenster, Muenster, Germany

${ }^{3}$ Research Program in Systems Oncology, Faculty of Medicine, University of Helsinki, Helsinki, Finland

\section{Correspondence}

Ursula Rescher, Institute of Medical

Biochemistry, Center for Molecular Biology of Inflammation and "Cells in Motion" Interfaculty Centre, University of Muenster, Von-Esmarch-Str. 56, D-48149, Muenster, Germany.

Email: rescher@uni-muenster.de

Funding information

Academy of Finland, Grant/Award Number: 317680; German Research Foundation (DFG); CRC 1348 "Dynamic Cellular Interfaces", Grant/Award Number: Project A10; CRC1009 "Breaking Barriers", Grant/Award Numbers: Project A6, Project B02, Lu477/23-1; European Research Council, Grant/Award Number: 716063; Innovative Medizinische Forschung (IMF) of the Münster Medical School, Grant/Award Number: SC121912; Interdisciplinary Center for Clinical Research Muenster (IZKF), Grant/Award Number: $\operatorname{Re} 2 / 022 / 20$
Background and Purpose: The SARS-COV-2 pandemic and the global spread of coronavirus disease 2019 (COVID-19) urgently call for efficient and safe antiviral treatment strategies. A straightforward approach to speed up drug development at lower costs is drug repurposing. Here, we investigated the therapeutic potential of targeting the interface of SARS CoV-2 with the host via repurposing of clinically licensed drugs and evaluated their use in combinatory treatments with virus- and host-directed drugs in vitro.

Experimental Approach: We tested the antiviral potential of the antifungal itraconazole and the antidepressant fluoxetine on the production of infectious SARS-CoV-2 particles in the polarized Calu-3 cell culture model and evaluated the added benefit of a combinatory use of these host-directed drugs with the direct acting antiviral remdesivir, an inhibitor of viral RNA polymerase.

Key Results: Drug treatments were well-tolerated and potently impaired viral replication. Importantly, both itraconazole-remdesivir and fluoxetine-remdesivir combinations inhibited the production of infectious SARS-CoV-2 particles $>90 \%$ and displayed synergistic effects, as determined in commonly used reference models for drug interaction.

Conclusion and Implications: Itraconazole-remdesivir and fluoxetine-remdesivir combinations are promising starting points for therapeutic options to control SARSCoV-2 infection and severe progression of COVID-19.

\section{KEYWORDS}

combination therapy, drug repurposing, fluoxetine, itraconazole, remdesivir, SARS-CoV-2

Abbreviations: COVID-19, coronavirus disease 2019; FluoRem, drug combination fluoxetine/remdesivir; ItraRem, drug combination itraconazole/remdesivir; MOI, multiplicity of infection; MTT, 3-(4,5-dimethylthiazol-2-yl)-2,5-diphenyltetrazolium bromide; SARS-CoV-2, severe acute respiratory syndrome related coronavirus 2; TMPRSS2, transmembrane protease serine 2.

This is an open access article under the terms of the Creative Commons Attribution-NonCommercial-NoDerivs License, which permits use and distribution in any medium, provided the original work is properly cited, the use is non-commercial and no modifications or adaptations are made.

(c) 2021 The Authors. British Journal of Pharmacology published by John Wiley \& Sons Ltd on behalf of British Pharmacological Society. 


\section{1 | INTRODUCTION}

The zoonotic coronavirus SARS-CoV-2 and the resulting coronavirus disease 2019 (COVID-19) pandemic impressively show the global threat potential of a newly emerging zoonotic pathogen. More than 2 million people have died so far from the current outbreak and the proportion of infected people was estimated to reach more than $10 \%$ of the global population, with still unpredictable fatality rates (Baud et al., 2020; Rajgor et al., 2020; Wu et al., 2020). Because of the pressing burden on national health systems and economic losses, safe and efficient treatment strategies are urgently required. While multiple candidate vaccines have been successfully developed in the last months, the rigorous testing and extensive clinical trials are timeconsuming processes and the production and distribution of effective and safe vaccines remain serious challenges. Thus, approaches other than immunization might offer useful additional options for the management and control of SARS-CoV-2 infection and the treatment of COVID-19 (Fierabracci et al., 2020). A possibility to speed up the availability of drugs for the treatment of novel infections is the use of drugs that are already in clinical use for unrelated diseases via the so-called "drug repurposing." Because their safety profiles, dosages and side effects are already known, this approach represents a promising strategy to identify antiviral drugs with faster clinical implementation and lower development costs, considerations that are especially important in the global COVID-19 pandemic (Pushpakom et al., 2018). In addition to drugs that directly target the virus, host cell components that are vitally important in the viral life cycle are explored as promising starting points for therapeutic intervention ("host cell-directed therapy") (lanevski et al., 2020; Schwegmann \& Brombacher, 2008; Zumla et al., 2020).

Although proteolytic cleavage of the SARS-CoV-2 spike surface protein by the host cell transmembrane protease serine 2 (TMPRSS2) enables SARS-CoV-2 to directly fuse with the plasma membrane, endocytosed SARS-CoV-2 particles use endosomeresiding proteases for fusion within endosomes (Tang et al., 2020). Both pathways contribute to the SARS-CoV-2 infection process and the preferential use of the actual fusion pathway might critically depend on the presence of plasma membrane proteases (Hoffmann et al., 2020). Our earlier research on influenza virus infection identified the late endosomal cholesterol balance as a critical factor in the influenza virus infection success and established this viral entry point as a possible pharmacological target. Elevated cholesterol levels inhibit the fusion of the influenza lipid envelope with the endosomal membranes and thus inhibit the efficient transfer of the viral genome into the host cytosol (Kühnl et al., 2018; Musiol et al., 2013). We found that the clinically licensed antifungal itraconazole, a triazole derivative that blocks the fungal ergosterol pathway, has antiviral properties against a range of viruses and is effective against influenzas $A$ virus infections in a preclinical mouse model (Schloer et al., 2019; Schloer, Goretzko, et al., 2020). This additional therapeutic function is most likely based on direct inhibition of the endosomal cholesterol transporter Niemann-Pick Type C1 (NPC intracellular cholesterol transporter 1; NPC1;

\section{What is already known}

- SARS-CoV-2 is susceptible to the broad-spectrum antiviral remdesivir.

- The antifungal itraconazole and the antidepressant fluoxetine can be repurposed to target enveloped viruses.

\section{What this study adds}

- Itraconazole, similar to fluoxetine, showed effective antiviral activity against SARS-CoV-2 infection in vitro,

- Combinatory treatments with itraconazole-remdesivir and fluoxetine-remdesivir displayed enhanced potency through synergy in vitro.

\section{What is the clinical significance}

- Combinatory treatments of itraconazole and fluoxetine along remdesivir might offer superior treatment to inhibit SARS-CoV-2.

SLC65A1) and the subsequent cholesterol storage (Schloer et al., 2019; Trinh et al., 2017).

The late endosome is an entry site for many zoonotically transmitted viruses, in particular for enveloped viruses including SARS-CoV-2 (Tang et al., 2020). Because of the functional similarities in transmitting the viral genome into the host cell, the same endosomal components might serve as pharmacological targets for a broad host-directed antiviral strategy against such viruses. Continuing our work on the endosomal host-virus interface, we explored whether a similar repurposing strategy could be used to impair SARS-CoV-2 entry and infection. Therefore, we assessed clinically licensed drugs that also affect endolysosomal lipid storage and cholesterol build-up for their antiviral potential. Here, we report that itraconazole treatment potently inhibited the production of SARSCoV-2 infectious particles. Together with our recently published work on the antiviral potential of the widely used 5-HT uptake inhibitor fluoxetine, which also negatively affects endosomal cholesterol release (Kornhuber et al., 2010; Schloer, Brunotte, et al., 2020) on SARS-CoV-2 infection, the results presented in this study strongly argue for the endolysosomal host-SARS-CoV-2 interface as a druggable target.

Combination therapy using several drugs that each target different molecular pathways is considered a key strategy to achieve therapeutic success with lower doses and a reduced likelihood of the development of drug resistance. Thus, we assessed the efficacy of a combined treatment using remdesivir, a nucleotide analogue prodrug that inhibits SARS-CoV-2 viral RNA-dependent RNA polymerase (Gordon et al., 2020) together with itraconazole or fluoxetine. Both two-drug combinations showed stronger antiviral activities 
against SARS-CoV-2 compared to remdesivir monotherapy (Schloer, Goretzko, et al., 2020) and pharmacodynamic evaluation via commonly used reference models to study drug interaction revealed synergistic interaction.

\section{2 | METHODS}

\subsection{Cells and SARS-CoV-2 isolate}

The human bronchial epithelial cell lines Calu-3 and the Vero E6 cells were cultivated in DMEM with $10 \%$ standardized FBS (FBS Superior; Merck), 2-mM L-glutamine, $100 \mathrm{U} \cdot \mathrm{ml}^{-1}$ penicillin, $0.1 \mathrm{mg} \cdot \mathrm{ml}^{-1}$ streptomycin and $1 \%$ non-essential amino acids (Merck) in a humidified incubator at $5 \% \mathrm{CO}_{2}$ and $37^{\circ} \mathrm{C}$. Calu-3 monolayers were polarized and cultured as described (Schloer, Goretzko, et al., 2020). Itraconazole (2 mg. $\mathrm{ml}^{-1}$, Sigma), fluoxetine (5 mM, Sigma) and remdesivir (10 mM, Hycultec) were solubilized in DMSO. The SARS-CoV-2 isolate hCoV19/Germany/FI1103201/2020 (EPI-ISL_463008, mutation D614G in spike protein) was amplified on Vero E6 cells and used for the infection assays.

\section{2 | Cytotoxicity assay}

Calu-3 cells were cultured at the indicated concentrations with either the solvent DMSO, itraconazole or with the combinations of itraconazole/remdesivir (ItraRem) or fluoxetine/remdesivir (FluoRem) for $48 \mathrm{~h}$. Staurosporine solution $(1 \mu \mathrm{M})$ served as a positive control for cytotoxic effects. After $48 \mathrm{~h}$ of treatment, cell viability was evaluated by adding 3-(4,5-dimethylthiazol-2-yl)-2,5-diphenyltetrazolium bromide (MTT) (Sigma) to the cells for $4 \mathrm{~h}$ and $\mathrm{OD}_{562}$ measurements according to the manufacturer's protocols (Sigma). Because the assay is based on the reduction of MTT to formazan crystals by $N A D(P) H$-dependent oxidoreductase enzymes in metabolically active cells, this colorimetric assay measures metabolic activity as an integrated indicator of changes in cell viability, cytotoxicity and proliferation.

\subsection{Inoculation of cells and drug treatment}

For infection, polarized Calu-3 and Vero E6 cells were washed with PBS and inoculated at a multiplicity of infection (MOI) of 0.1 (Calu-3) or 0.01 (Vero E6) of virus diluted in infection-PBS (containing $0.2 \%$ BSA, $1 \% \mathrm{CaCl}_{2}, 1 \% \mathrm{MgCl}_{2}, 100 \mathrm{U} \cdot \mathrm{ml}^{-1}$ penicillin and $0.1 \mathrm{mg} \cdot \mathrm{ml}^{-1}$ streptomycin) at $37^{\circ} \mathrm{C}$ for $1 \mathrm{~h}$. Subsequently, cells were washed with PBS and further cultured in infection-DMEM (serum-free DMEM containing $0.2 \% \mathrm{BSA}, 1-\mathrm{mM} \mathrm{MgCl} 2,0.9-\mathrm{mM} \mathrm{CaCl}_{2}, 100 \mathrm{U} \cdot \mathrm{ml}^{-1}$ penicillin and $0.1 \mathrm{mg} \cdot \mathrm{ml}^{-1}$ streptomycin) at $5 \% \mathrm{CO}_{2}$ and $37^{\circ} \mathrm{C}$. Cells were treated with the indicated remdesivir, itraconazole or fluoxetine concentration $2 \mathrm{~h}$ post-infection (hpi) for the entire 48-h infection period. After $48 \mathrm{hpi}$, apical culture supernatants were collected and immediately frozen at $-80^{\circ} \mathrm{C}$ until titration via plaque assay.

\subsection{Plaque assay}

To determine the number of infectious particles in the supernatant of treated cells, a standard plaque assay was performed. Briefly, Vero E6 cells grown to a monolayer in six-well dishes were washed with PBS and infected with serial dilutions of the respective supernatants in infection-PBS for $1 \mathrm{~h}$ at $37^{\circ} \mathrm{C}$. The inoculum was replaced with $2 \times$ MEM (MEM containing 0.2\% BSA, 2-mM L-glutamine, 1-M HEPES, $\mathrm{pH} 7.2,7.5 \% \mathrm{NaHCO}_{3}, 100 \mathrm{U} \cdot \mathrm{ml}^{-1}$ penicillin, $0.1 \mathrm{mg} \cdot \mathrm{ml}^{-1}$ streptomycin and $0.4 \%$ Oxoid agar) and incubated at $37^{\circ} \mathrm{C}$. Virus plaques were visualized by staining with neutral red and virus titres were calculated as plaque-forming units (PFU) per $\mathrm{ml}$.

\section{5 | Data and statistical analysis}

The data and statistical analysis comply with the recommendations of the British Journal of Pharmacology (Curtis et al., 2018) on experimental design and analysis in pharmacology. A priori power analysis using G*Power 3.1 (RRID:SCR_013726, Faul et al., 2007) was performed to determine the sample sizes required to detect $>90 \%$ reduction in virus titres at powers $>0.8$. Data were analysed using the software GraphPad Prism version 8.00 (GraphPad, RRID:SCR_002798). No outliers were detected.

Infectious viral titres are presented as means \pm SEM of five measurements per experiment per condition. For dose-response curves, drug concentrations were log-transformed and virus titres were expressed as percentages of the mean virus titre in control cells (treated with the solvent DMSO) and data were analysed by curve fitting using a four-parameter logistic model. Drug combinatory effects were analysed by using SynergyFinder (RRID: SCR_019318), an open-source free stand-alone web application for the analysis of drug combination data (lanevski et al., 2017). Synergy was evaluated based on the zero interaction potency (ZIP), Bliss independence and highest single agent reference models (He et al., 2018). We further analysed the overall drug combination sensitivity score by using the combination sensitivity score method (Malyutina et al., 2019).

\subsection{Materials}

Itraconazole, Fluoxetine, DMSO, Staurosporine and MTT assay were obtained from Sigma, Remdesivir was purchased from Hyculture.

\subsection{Nomenclature of targets and ligands}

Key protein targets and ligands in this article are hyperlinked to corresponding entries in the IUPHAR/BPS Guide to PHARMACOLOGY http://www.guidetopharmacology.org and are permanently archived in the Concise Guide to PHARMACOLOGY 2019/20 (Alexander, Fabbro, et al., 2019; Alexander, Kelly, et al., 2019). 


\section{3 | RESULTS}

\section{1 | The clinically licensed antifungal drug itraconazole efficiently blocks the production of SARS- CoV-2 infectious particles}

Based on the successful repurposing of itraconazole for the treatment of influenza virus infection reported in our earlier studies (Schloer et al., 2019; Schloer, Goretzko, et al., 2020), we first established whether this clinically licensed drug also had an antiviral potential on the production of infectious SARS-CoV-2 particles. In line with our previous results (Schloer, Brunotte, et al., 2020), both Calu-3 and Vero E6 cell lines supported SARS-CoV-2 replication and produced high virus titres (Figure 1). Inoculation with the clinical isolate hCoV-19/ Germany/FI1103201/2020 at multiplicity of infection (MOI) 0.1 yielded $1.46 \times 10^{6} \mathrm{PFU}$ in Calu-3 cells and $6.37 \times 10^{6} \mathrm{PFU}$ at $\mathrm{MOI}$ 0.01 in Vero cells at 48 hours post-infection. Treatment with itraconazole 2 hours post-infection potently inhibited SARS-CoV-2 replication in a dose-dependent manner in both cell types (Figure 1a). Fitting the experimental dose-response values to a non-linear fourparameter logistic model revealed half-maximal inhibitory $\left(\mathrm{EC}_{50}\right)$ and $90 \%$ inhibitory concentrations ( $\mathrm{EC}_{90}$ ) of 0.43 and $2.46 \mu \mathrm{M}$ in Calu-3 cells and even lower $50 \%$ and $90 \%$ inhibitory concentrations $(0.39$ and $0.87 \mu \mathrm{M}$ ) were determined for itraconazole antiviral activity in SARS-CoV-2 infected Vero cells (Figure 1b). Of note, no detectable cytotoxicity was observed with these doses (Figure S1a). The itraconazole cytotoxic concentration required to reduce cell viability by $50 \%\left(\mathrm{CC}_{50}\right)$ was determined at $25.56 \mu \mathrm{M}$, resulting in a selectivity index (SI; defined as the ratio of $\mathrm{CC}_{50}$ to $\mathrm{EC}_{50}$ ) of $25.56 \mu \mathrm{M}$ which indicated an effective and safe antiviral window.

\section{2 | Remdesivir inhibits SARS-CoV-2 replication in polarized Calu- 3 cells}

We addressed the question of whether a host-targeting drug could be used in combination with a virus-directed drug for more efficient suppression of SARS-CoV-2 replication. Thus, we first assessed the antiviral capacity of remdesivir. The $\mathrm{EC}_{50}$ concentration was reached at $0.42 \mu \mathrm{M}$ and $\mathrm{EC}_{90}$ at $1.08 \mu \mathrm{M}$ in Calu-3 cells (Figure S2), well in line with published data (Pruijssers et al., 2020). Next, we determined viral replication in cells that had been treated with a combination of both drugs. Because we recently published the potential use of repurposing the antidepressant fluoxetine for treatment of SARS-CoV-2 infection
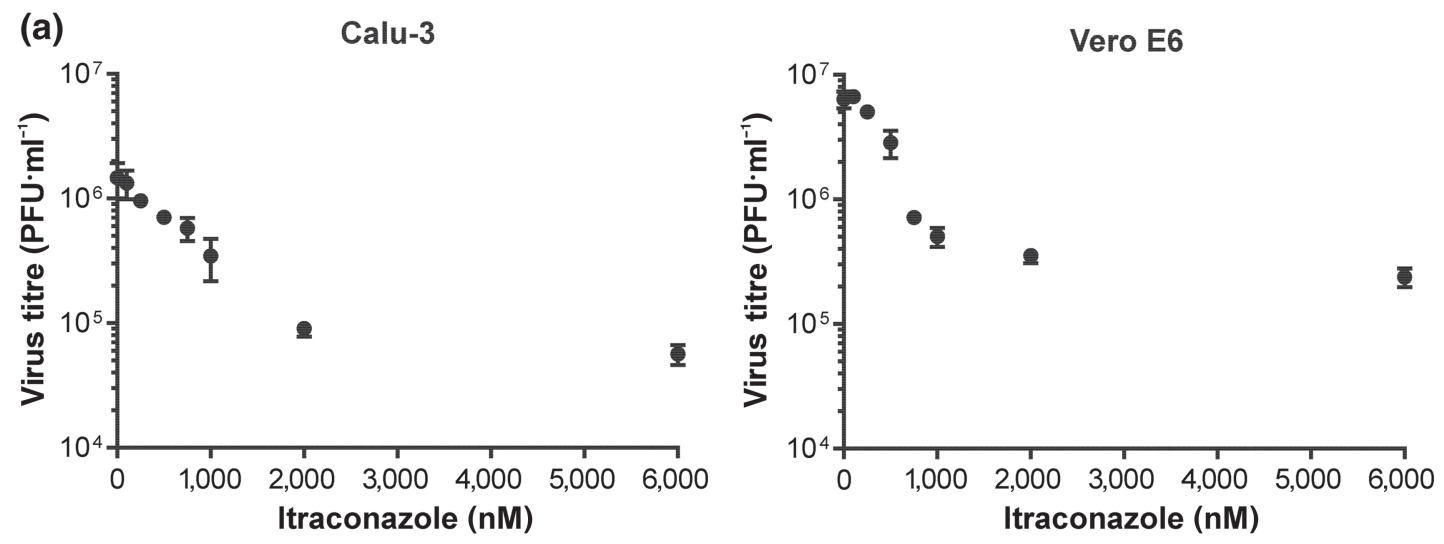

(b)

Calu-3

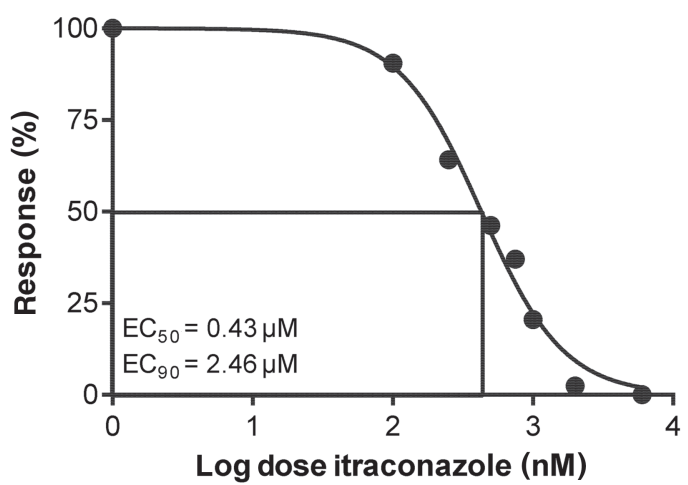

Vero E6

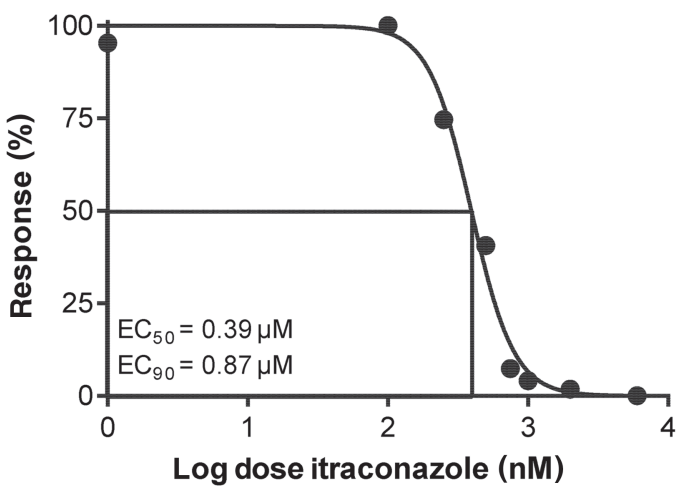

FIGURE 1 Analysis of itraconazole-mediated reduction of SARS-CoV-2 replication. Calu-3 and Vero E6 cells were infected with 0.1 multiplicity of infection (MOI) of SARS-CoV-2. At 2 hours post-infection (hpi), cells were treated with itraconazole at the indicated concentrations. (a) Mean infectious viral titres \pm SEM, (b) mean per cent inhibition \pm SEM of SARS-CoV- 2 replication, with mean virus titre in control cells (treated with the solvent DMSO) set to $100 \% ; n=5$. LogEC 50 and LogEC 90 values were determined by fitting a four-parameter nonlinear regression model (Calu-3: $\mathrm{EC}_{50}=0.43 \mu \mathrm{M}, \mathrm{EC}_{90}=2.46 \mu \mathrm{M}$; Vero $\left.\mathrm{E}: \mathrm{EC}_{50}=0.39 \mu \mathrm{M}, \mathrm{EC}_{90}=0.87 \mu \mathrm{M}\right)$ 
(Schloer, Brunotte, et al., 2020), we also assessed the effects of a combined fluoxetine/remdesivir (FluoRem) treatment in addition to the itraconazole/remdesivir (ItraRem) combination (Figure 2). Both drugs are clinically licensed and do not induce significant cytotoxicity over the whole concentration range (Schloer, Brunotte, et al., 2020; Figure S1a). The combination treatments were also well tolerated and no cytotoxic effects were seen when cells were simultaneously treated with the drug pairs, thus excluding synergistic toxicity (Figure S1b,c).

\subsection{Combinatory treatments with the drug pairs itraconazole-remdesivir and fluoxetine-remdesivir show enhanced antiviral activity due to synergistic interaction}

For all drugs, we chose those concentrations that were not sufficient to achieve a $90 \%$ reduction when individually applied (Figure 3a). For both ItraRem and FluoRem combinations, a potent reduction in virus titres was detected in all cases. Of note, several combinations yielded a reduction $>90 \%$ of the maximum virus titres produced in control cells (Figure $3 b$ ).

We next considered the pharmacological interactions of the respective drug pairs. Thus, we evaluated the drug interactions via Bliss independence, highest single agent and zero interaction potency, three commonly used reference synergy models that differ in their basic assumptions of drug interaction they are based on. The results, presented in Figures 4 and 5, consistently argued for synergistic action of remdesivir with itraconazole and fluoxetine, as indicated by the positive average synergy score across all models. Closer inspection of the drug interaction relationships and landscape visualizations revealed that for ItraRem, the highest synergy scores were calculated with the lower concentration ranges of both drugs (Figure 4). The strong synergy led to an overall drug combination sensitivity score of 89.64 , resulting in $>90 \%$ inhibition already at $500 \mathrm{nM}$ of remdesivir

(a)

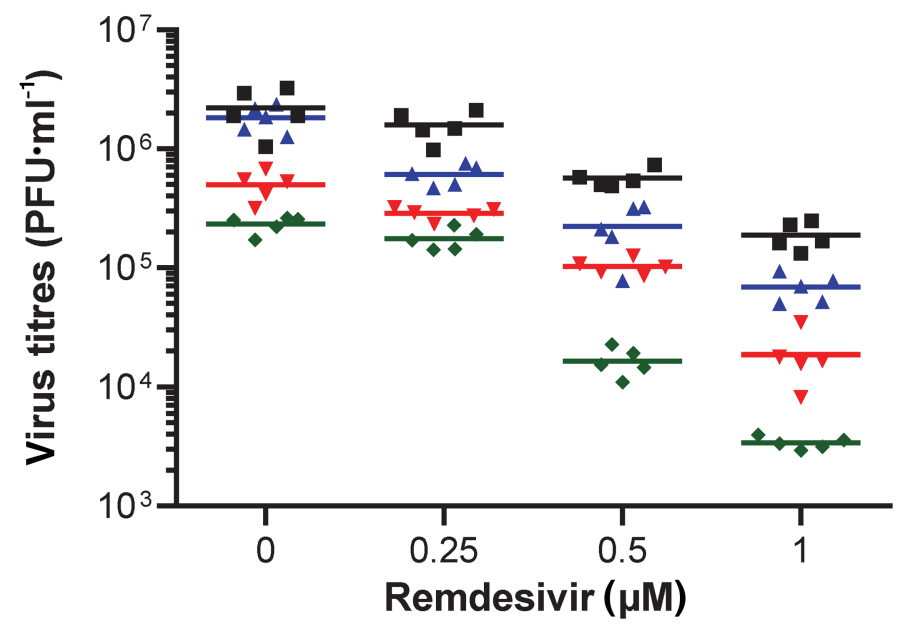

- Itraconazole $1 \mu \mathrm{M}$

$\checkmark$ Itraconazole $0.5 \mu \mathrm{M}$

$\Delta$ Itraconazole $0.25 \mu \mathrm{M}$

- Itraconazole $0 \mu \mathrm{M}$

(b)

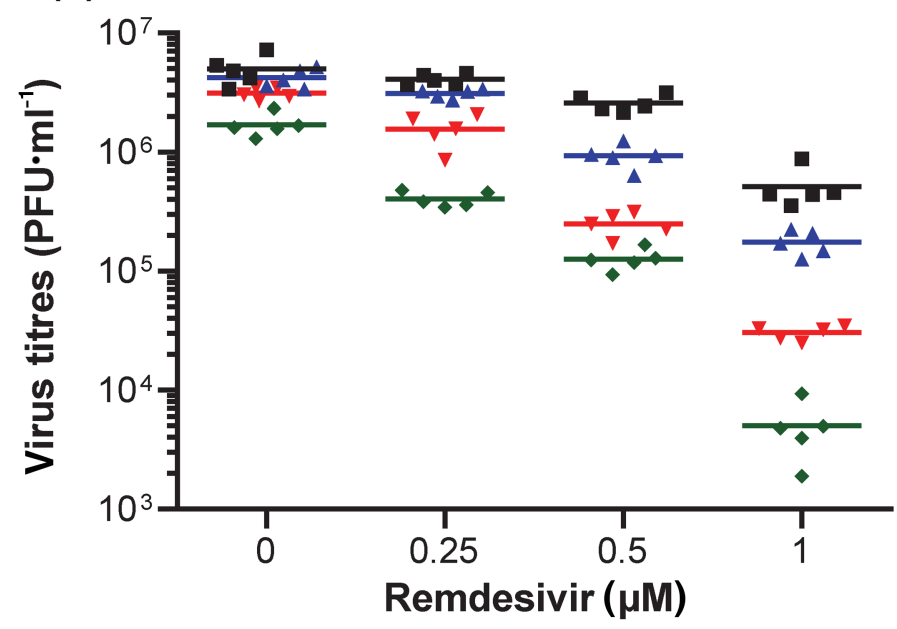

- Fluoxetine $2.5 \mu \mathrm{M}$

v Fluoxetine $1 \mu \mathrm{M}$

- Fluoxetine $0.5 \mu \mathrm{M}$

- Fluoxetine $0 \mu \mathrm{M}$

FIGURE 2 Antiviral activities of treatments. Infectious virus production in polarized Calu-3 cells treated with two-drug combinations as indicated 2 hours post-infection (hpi). Each symbol represents plaque-forming units (PFU) per $\mathrm{ml}$ detected in a single experimental sample; lines indicate means; $n=5$ per treatment 
(a)

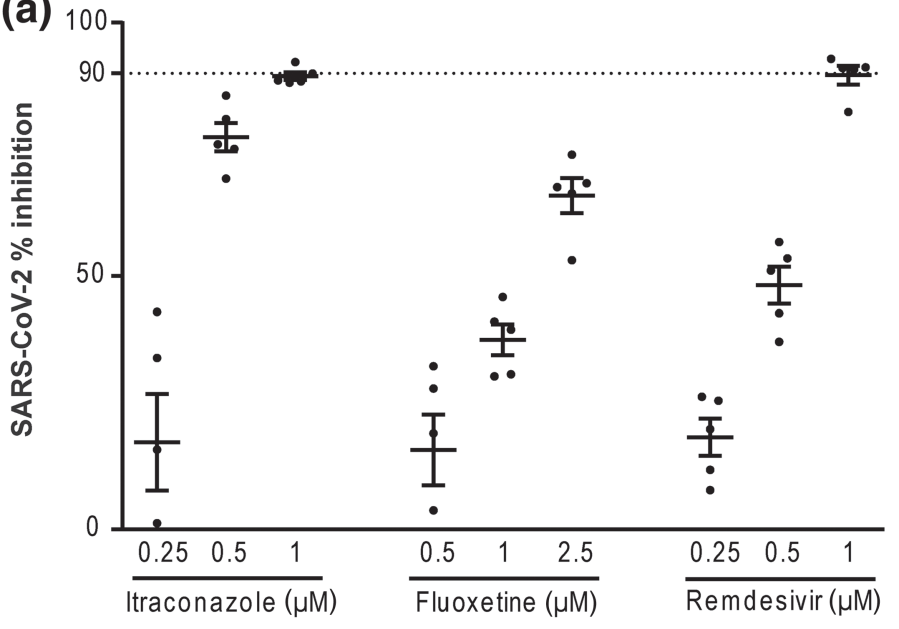

(b)

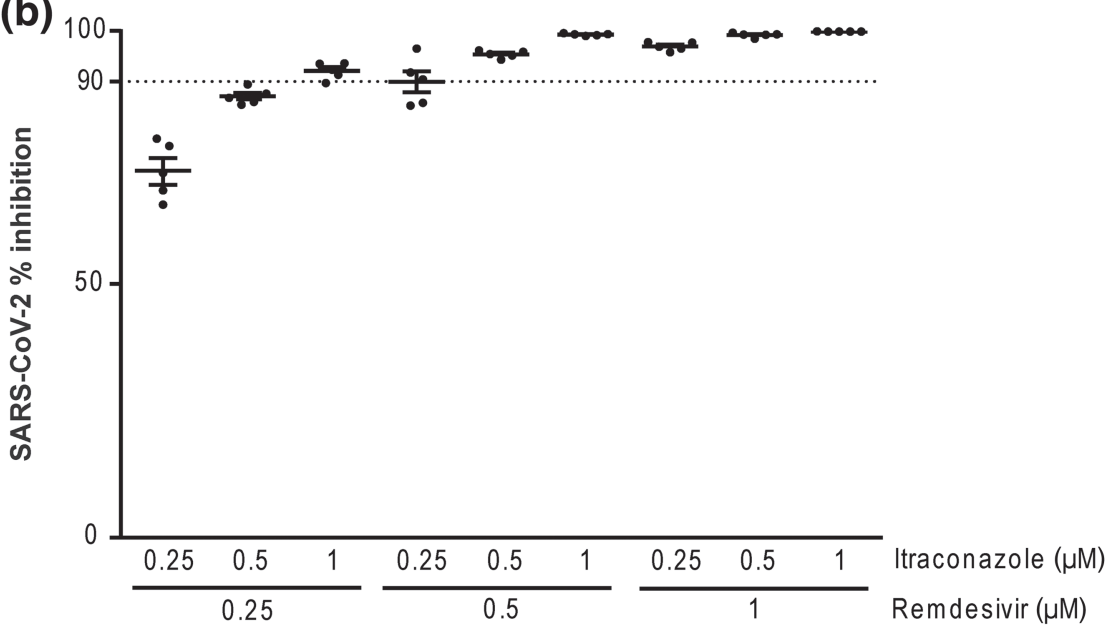

FIGURE 3 Antiviral activities of single and combination treatments. Polarized Calu- 3 cells were treated with the indicated drug combinations for 48 h. (a) Single treatment; (b) combinatory treatment. Each symbol represents mean per cent inhibition \pm SEM of infectious virus production, with mean virus titre produced in control cells (treated with the solvent DMSO) set to $100 \% ; n=5$. Dotted line, $90 \%$ reduction in viral titre

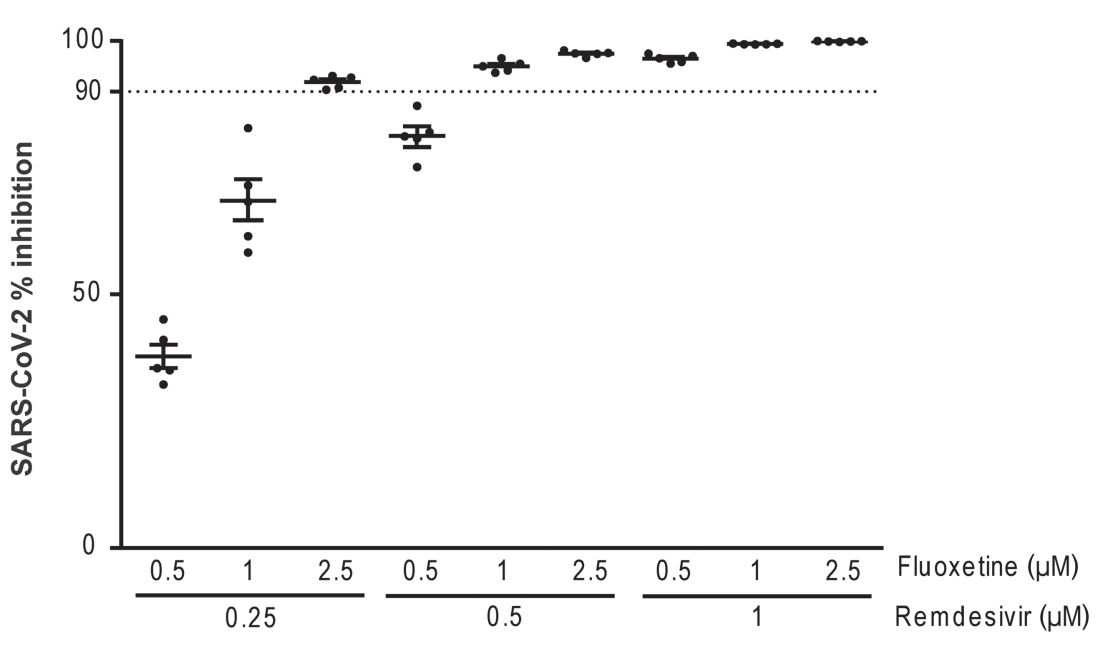

and $250 \mathrm{nM}$ of itraconazole. FluoRem combination treatment had a higher average synergy score, as well as a higher combination sensitivity score than ItraRem (92.82 vs. 89.64), suggesting that this drug combination is more likely to show synergy. Importantly, for all models, the FluoRem combinations that met the $\geq 90 \%$ inhibition criterion were well within the high synergy area (Figure 5).

\section{4 | DISCUSSION}

To combat the current global health emergency caused by the SARSCoV-2 pandemics, vaccines and antivirals are urgently needed. Entry of enveloped viruses such as SARS-CoV-2 into a host cell depends on the fusion of their lipid hull with the host membrane and the transfer 

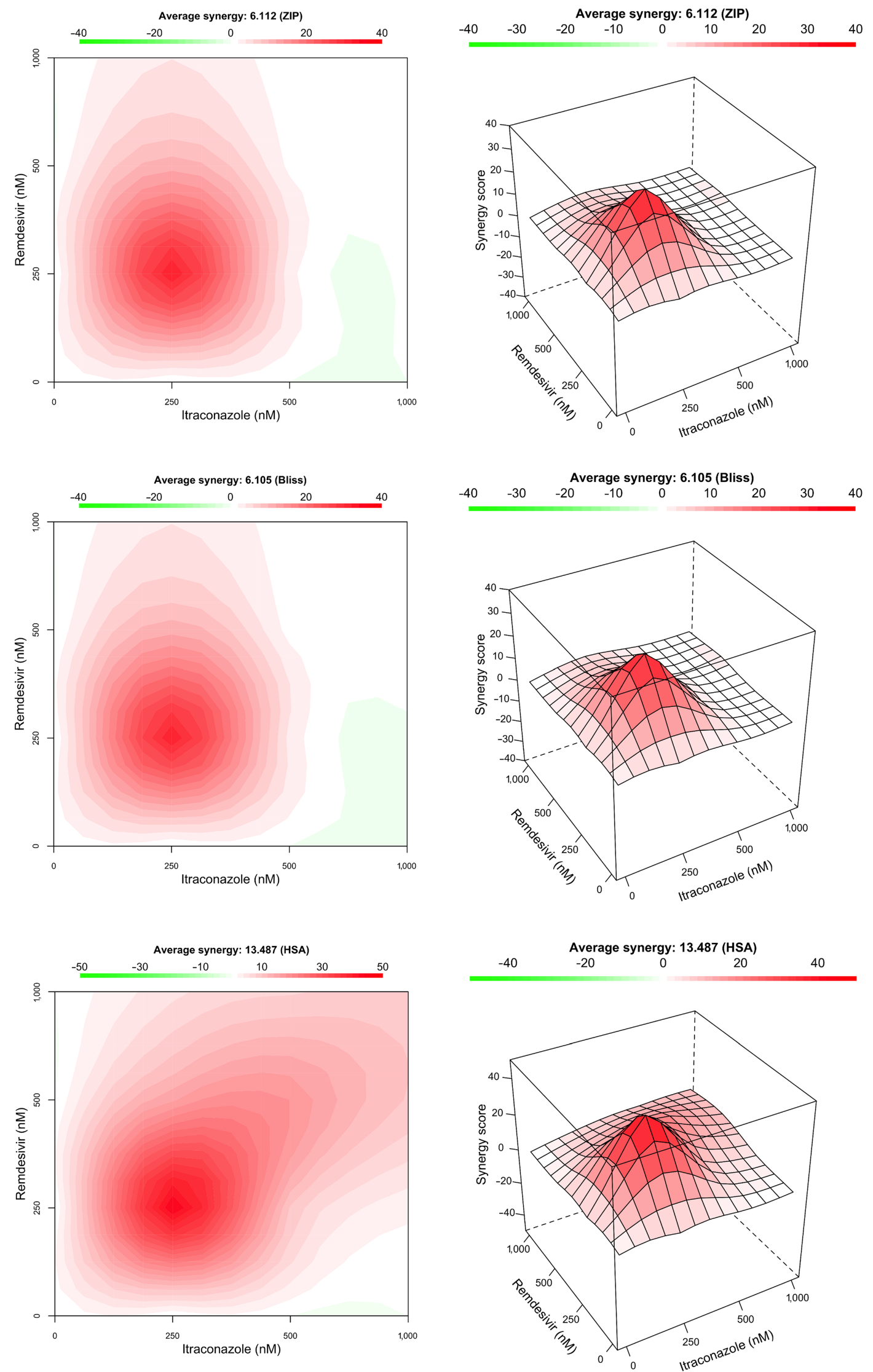

FIGURE 4 Evaluation of the pharmacological interactions of itraconazole and remdesivir (ItraRem). zero interaction potency (ZIP), Bliss independence and highest single agent (HSA) reference models were used to assess the interaction landscapes and to identify areas of synergy. Interaction surfaces are colour coded according to the synergy scores of the responses 

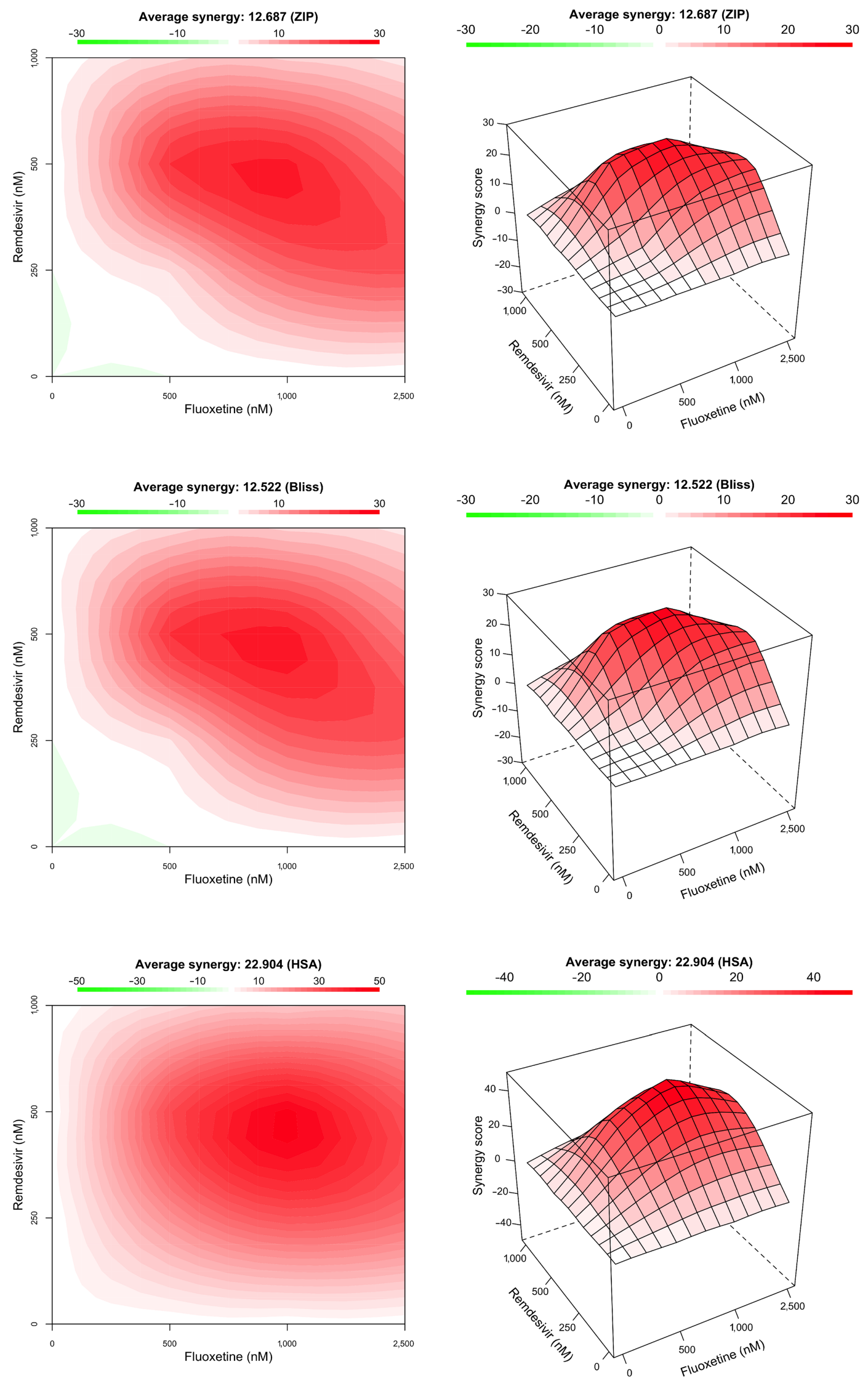

FIGURE 5 Evaluation of the pharmacological interactions of fluoxetine and remdesivir (FluoRem). zero interaction potency (ZIP), Bliss independence and highest single agent (HSA) reference models were used to assess the interaction landscapes and to identify areas of synergy. Interaction surfaces are colour coded according to the synergy scores of the responses 
of the viral genome into the cytosol. The SARS-CoV-2 spike protein, which protrudes from the virus surface, mediates initial binding to ACE2, which serves as the host cell surface receptor (Lan et al., 2020; Li et al., 2003; Ou et al., 2020; Zhou et al., 2020). To promote fusion with the host cell membrane, the spike protein needs to be primed by proteolytic cleavage, which can be mediated by several host proteases. TMPRSS2-mediated cleavage leads to fusion with the plasma membrane, while endosome-residing proteases are utilized by endocytosed SARS-CoV-2 particles for fusion within endosomes. Since both routes have been reported to contribute to the SARS-CoV-2 infectivity (Hoffmann et al., 2020), the endosomal compartment is also a critical host/pathogen interface for SARS-CoV-2. Our previous studies strongly support the late endosomal cholesterol balance as a cellular target for antiviral intervention (Kühnl et al., 2018; Musiol et al., 2013; Schloer et al., 2019; Schloer, Brunotte, et al., 2020; Schloer, Goretzko, et al., 2020). Notably, our previous reports showed that endolysosomal lipid storage and cholesterol build-up could be induced via repurposing of drugs approved for unrelated applications. We found that the triazole derivative itraconazole, a clinically licensed antifungal drug (World Health Organization, 2019) that directly inhibits the endosomal cholesterol transporter Niemann-Pick Type C1 (Trinh et al., 2017), has an antiviral potential on the endosomal fusion of enveloped viruses including influenza viruses (Schloer et al., 2019). Moreover, our previous study already revealed a beneficial antiviral activity in vivo (Schloer et al., 2019).

The findings presented in this study add SARS-CoV-2 to the spectrum of itraconazole-sensitive enveloped viruses. Our results reveal a potent antiviral activity of itraconazole on the production of SARSCoV-2 infectious particles, with $\mathrm{EC}_{50}$ values comparable to what we previously reported for itraconazole-mediated antiviral activity against IAV subtypes (Schloer et al., 2019; Schloer, Goretzko, et al., 2020). The bioavailability after oral application of itraconazole is low because of the low water solubility of this highly lipophilic compound (Domínguez-Gil Hurlé et al., 2006; Grant Prentice \& Glasmacher, 2005). Because the slightly acidic salt is ionized only at very low $\mathrm{pH}$, fluctuations in individual gastric acidity, for example fasting conditions or medications, reduce the bioavailability. Food or acidic beverages can influence the adsorption of orally administered itraconazole, depending on the formulation. Only limited amounts are absorbed from the gastrointestinal tract, leading to high interpatient variability in plasma levels (Allegra et al., 2017; Bae et al., 2011; Domínguez-Gil Hurlé et al., 2006; Lestner \& Hope, 2013; Shin et al., 2004). Yet itraconazole has been proven to be clinically useful in the prophylaxis and treatment of fungal infections, with a recommended daily dose of 200-400 mg.day ${ }^{-1}$, which might be increased up to $600 \mathrm{mg} \cdot$ day $^{-1}$ in case of severe infections. Effective plasma concentration ranges in patients with pulmonary aspergillosis treated with 200-mg itraconazole once daily have been reported to begin at $500 \mu \mathrm{g} \cdot \mathrm{L}^{-1}$, well above the $\mathrm{EC}_{50}$ levels for anti-SARS-CoV-2 antiviral activity determined in this study. We recently also discovered that the widely used antidepressant fluoxetine has strong SARSCoV-2 antiviral activity (Schloer, Brunotte, et al., 2020). In contrast to itraconazole, the bioavailability of orally administered fluoxetine is high, having plasma levels of $350 \mu \mathrm{g} \cdot \mathrm{L}^{-1}$ after 2 weeks and up to $1,055 \mu \mathrm{g} \cdot \mathrm{L}^{-1}$ after longer treatment periods were reported in patients on $20 \mathrm{mg}$ day $^{-1}$ fluoxetine (Pope \& Zaraa, 2016; Preskorn et al., 1991), levels that we found sufficient to inhibit over $50 \%$ of SARS-CoV-2 virus titres. Interestingly, fluoxetine is a racemic mixture of two enantiomers both of which have been reported to exert antiviral activity (Zimniak et al., 2020), which might allow for the development of antiviral derivatives that do not affect serotonin re-uptake.

Together with the findings presented here on the inhibitory function of itraconazole treatment on SARS-CoV-2 replication, these results suggest that both drugs are promising candidates for repurposing as a host-directed drug for SARS-CoV-2 infection treatment. Both drugs most likely interfere with the proper endosomal cholesterol levels. Whereas itraconazole and posaconazole both directly inhibit the endosomal cholesterol transporter Niemann-Pick Type C1 (Trinh et al., 2017), fluoxetine functionally blocks the endolysosome-residing enzyme sphingomyelin phosphodiesterase (acid sphingomyelinase), which in turn causes sphingomyelin accumulation and negatively affects cholesterol release from this compartment (Kornhuber et al., 2010). However, host-directed drugs will rather cause impaired viral replication and suppress infection than completely eradicate the pathogen. The resulting demand for high drug doses and early and prolonged treatment is often associated with poor patient compliance.

While drugs directly acting on virus structures are much more likely to completely eliminate the pathogens in shorter treatment time, a major concern about virus-directed antivirals is the development of drug resistance. As observed with the influenza neuraminidase inhibitor oseltamivir (Kim et al., 2013), viruses that evolve resistance mechanisms to evade the antiviral activity are increasingly emerging (Strasfeld \& Chou, 2010). Because profound changes would be required to allow viruses to replicate independently of otherwise essential host factors, combinatory treatments with both virus- and host-directed drugs are considered to overcome these shortcomings and are routinely explored for enhanced treatment success. The nucleoside analogue remdesivir, which was originally developed against Ebola (Warren et al., 2016), is a direct acting antiviral that interferes with the viral RNA-dependent RNA polymerase. When remdesivir is incorporated into the viral RNA the synthesis is prematurely terminated and viral replication is inhibited (Gordon et al., 2020). Remdesivir exerts antiviral activity against a range of viruses including Ebola, Marburg and MERS and is also active against SARS-CoV-2 (Agostini et al., 2018; Brown et al., 2019; Sheahan et al., 2017, 2020; Warren et al., 2016). Indeed, remdesivir was the first new drug to receive an FDA emergency use authorization for the treatment of severe COVID-19 cases, although its clinical use is still controversially. A major obstacle is the very short half-life, with initial peak serum concentrations of about $3 \mathrm{mg} \cdot \mathrm{L}^{-1}$ measured directly after intravenous infusion rapidly declining to $80-170 \mu \mathrm{g} \cdot \mathrm{L}^{-1}$ after $1 \mathrm{~h}$ (Tempestilli et al., 2020). Yet recently published results of doubleblind, randomized, placebo-controlled trials suggest that remdesivir treatment is beneficial in the treatment of hospitalized COVID-19 patients and might be improved further by combination therapy with 
remdesivir and the host-directed Janus kinase inhibitor baricitinib (Beigel et al., 2020; Kalil et al., 2020). Interestingly, GS-441524, the predominant remdesivir metabolite in the plasma which has a considerably longer half-life, has been reported to potently inhibit SARS-CoV-2 replication in vitro as well as in a mouse model of SARS-CoV-2 infection and pathogenesis (Li et al., 2020), making this metabolite a promising drug candidate.

Here, we report that ItraRem and FluoRem drug combinations, in both cases targeting the host cell and the virus independently, showed stronger antiviral activities against SARS-CoV-2 than the remdesivir monotherapy. Moreover, the overall therapeutic effect of the combinations was larger than the expected sum of the independent drug effects and underlying synergistic effects were determined, allowing for lower concentrations of the individual drugs. Of note, their reported plasma concentrations are well within these ranges.

While our results support the use of the direct antiviral remdesivir in combination with a host-directed drug as a potential therapeutic strategy to reduce SARS-CoV-2 infection success and to limit deleterious COVID-19 outcomes, the translation of in vitro results into the clinics remains a major challenge. Although pharmacokinetic and safety profiles for these drugs are available, combined medications bear the risk of drug-drug interactions which may lead to reduced therapeutic benefit or even severe adverse effects. Therefore, it is important to mention that a vast number of drugs are currently known to interact with itraconazole, fluoxetine and even remdesivir (information available at Drugs.com 2021). Furthermore, the patient's genetic disposition and physiological or pathophysiological conditions demand for a careful evaluation of the appropriate treatment strategy. Thus, it is paramount to evaluate the patient-related risks and benefits, as coadministration of drugs might be contraindicated in certain patients.

\section{5 | CONCLUSION}

Our analysis on the antiviral activity of combinatory drug combinations via commonly used interaction models argues for an enhanced efficacy that is based on synergistic drug interaction and suggests promising novel options for SARS-CoV-2 treatment.

\section{ACKNOWLEDGEMENTS}

We thank Jonathan Hentrey for help with the plaque assays. This research was funded by grants from the German Research Foundation (DFG), CRC 1009 "Breaking Barriers," Project A06 (to U.R.) and B02 (to S.L.), CRC 1348 "Dynamic Cellular Interfaces," Project A11 (to U.R.) and DFG Lu477/23-1 (to S.L.), the European Research Council No. 716063 (to S.Z. and J.T.), the Academy of Finland No. 317680 (to S.Z. and J.T.), the Interdisciplinary Center for Clinical Research (IZKF) of the Münster Medical School, grant number Re2/022/20 (to U.R.) and the Innovative Medizinische Forschung (IMF) of the Münster Medical School, grant number SC121912 (to S.S.).

\section{AUTHOR CONTRIBUTIONS}

Conceptualization and methodology: S.S. and U.R.; validation, formal analysis, investigation and data curation: S.S., J.T and U.R.; resources: J.T. S.L. and U.R.; writing-original draft preparation: U.R.; writingreview and editing: S.S., S.L. and U.R.; visualization: S.S.; supervision: U.R. and S.L.; project administration: U.R.; funding acquisition: U.R. All authors have read and agreed to the published version of the manuscript.

\section{CONFLICT OF INTEREST}

The authors declare no conflict of interest. The funders had no role in the design of the study; in the collection, analyses or interpretation of data; in the writing of the manuscript; or in the decision to publish the results. S.S., S.L. and U.R. are members of the German FluResearchNet, a nationwide research network on zoonotic influenza. S.S. and U.R. are members of the British Pharmacological Society.

\section{DECLARATION OF TRANSPARENCY AND SCIENTIFIC RIGOUR}

This Declaration acknowledges that this paper adheres to the principles for transparent reporting and scientific rigour of preclinical research as stated in the BJP guidelines for Design \& Analysis and as recommended by funding agencies, publishers and other organizations engaged with supporting research.

\section{DATA AVAILABILITY STATEMENT}

The data that support the findings of this study are available from the corresponding author upon reasonable request. Some data may not be made available because of privacy or ethical restrictions.

\section{ORCID}

Linda Brunotte (D) https://orcid.org/0000-0001-8074-7400

Jing Tang (D) https://orcid.org/0000-0001-7480-7710

Stephan Ludwig (D) https://orcid.org/0000-0003-4490-3052

Ursula Rescher (DD) https://orcid.org/0000-0001-8892-319X

\section{REFERENCES}

Agostini, M. L., Andres, E. L., Sims, A. C., Graham, R. L., Sheahan, T. P., Lu, X., Smith, E. C., Case, J. B., Feng, J. Y., Jordan, R., Ray, A. S., Cihlar, T., Siegel, D., Mackman, R., Clarke, M., Baric, R., \& Denison, M. (2018). Coronavirus susceptibility to the antiviral remdesivir (GS-5734) is mediated by the viral polymerase and the proofreading exoribonuclease. MBio, 9, 00221-18.

Alexander, S. P. H., Fabbro, D., Kelly, E., Mathie, A., Peters, J. A., Veale, E. L., Armstrong, J. F., Faccenda, E., Harding, S. D., Pawson, A. J., \& Sharman, J. L. (2019). The Concise Guide to PHARMACOLOGY 2019/20: Enzymes. British Journal of Pharmacology, 176, S297-S396.

Alexander, S. P. H., Kelly, E., Mathie, A., Peters, J. A., Veale, E. L., Armstrong, J. F., Faccenda, E., Harding, S. D., Pawson, A. J., Sharman, J. L., \& Southan, C. (2019). The Concise Guide to PHARMACOLOGY 2019/20: Transporters. British Journal of Pharmacology, 176, S397-S493.

Allegra, S., Fatiguso, G., De Francia, S., Favata, F., Pirro, E., Carcieri, C., De Nicolò, A., Cusato, J., Di Perri, G., \& D'Avolio, A. (2017). Evaluation of 
posaconazole pharmacokinetics in adult patients with invasive fungal infection. Biomedicine, 5(4), 66.

Bae, S. K., Park, S.-J., Shim, E.-J., Mun, J.-H., Kim, E.-Y., Shin, J.-G., \& Shon, J. H. (2011). Increased oral bioavailability of itraconazole and its active metabolite, 7-hydroxyitraconazole, when coadministered with a vitamin C beverage in healthy participants. Journal of Clinical Pharmacology, 51, 444-451. https://doi.org/10.1177/0091270010365557

Baud, D., Qi, X., Nielsen-Saines, K., Musso, D., Pomar, L., \& Favre, G. (2020). Real estimates of mortality following COVID-19 infection. The Lancet Infectious Diseases, 20(7), 773. https://doi.org/10.1016/S14733099(20)30195-X

Beigel, J. H., Tomashek, K. M., Dodd, L. E., Mehta, A. K., Zingman, B. S., Kalil, A. C., Hohmann, E., Chu, H. Y., Luetkemeyer, A., Kline, S., Lopez de Castilla, D., Finberg, R. W., Dierberg, K., Tapson, V., Hsieh, L., Patterson, T. F., Paredes, R., Sweeney, D. A., Short, W. R., ... ACTT-1 Study Group Members. (2020). Remdesivir for the treatment of Covid19-Final report. The New England Journal of Medicine, 383, 1813-1826. https://doi.org/10.1056/NEJMoa2007764

Brown, A. J., Won, J. J., Graham, R. L., Dinnon, K. H., Sims, A. C., Feng, J. Y., Cihlar, T., Denison, M. R., Baric, R. S., \& Sheahan, T. P. (2019). Broad spectrum antiviral remdesivir inhibits human endemic and zoonotic deltacoronaviruses with a highly divergent RNA dependent RNA polymerase. Antiviral Research, 169, 104541. https://doi. org/10.1016/j.antiviral.2019.104541

Curtis, M. J., Alexander, S., Cirino, G., Docherty, J. R., George, C. H., Giembycz, M. A., ... Ahluwalia, A. (2018). Experimental design and analysis and their reporting II: Updated and simplified guidance for authors and peer reviewers. British Journal of Pharmacology, 175(7), 987-993. https://doi.org/10.1111/bph.14153

Domínguez-Gil Hurlé, A., Sánchez Navarro, A., \& García Sánchez, M. J. (2006). Therapeutic drug monitoring of itraconazole and the relevance of pharmacokinetic interactions. Clinical Microbiology and Infection, 12, 97-106. https://doi.org/10.1111/j.1469-0691.2006.01611.x

Drugs.com [Internet]. Drug Interaction Checker from Drugs.com; c1996-2018 [last updated: 2 Nov 2020 cited: 21 Jan 2021]. https:// www.drugs.com/drug_interactions.html

Faul, F., Erdfelder, E., Lang, A.-G., \& Buchner, A. (2007). G*Power 3: A flexible statistical power analysis program for the social, behavioral, and biomedical sciences. Behavior Research Methods, 39, 175-191. https:// doi.org/10.3758/BF03193146

Fierabracci, A., Arena, A., \& Rossi, P. (2020). COVID-19: A review on diagnosis, treatment, and prophylaxis. International Journal of Molecular Sciences, 21, 1-16.

Gordon, C. J., Tchesnokov, E. P., Woolner, E., Perry, J. K., Feng, J. Y., Porter, D. P., \& Götte, M. (2020). Remdesivir is a direct-acting antiviral that inhibits RNA-dependent RNA polymerase from severe acute respiratory syndrome coronavirus 2 with high potency. The Journal of Biological Chemistry, 295, 6785-6797. https://doi.org/10.1074/jbc. RA120.013679

Grant Prentice, A., \& Glasmacher, A. (2005). Making sense of itraconazole pharmacokinetics. The Journal of Antimicrobial Chemotherapy, 56, 17-22.

He, L., Kulesskiy, E., Saarela, J., Turunen, L., Wennerberg, K., Aittokallio, T., \& Tang, J. (2018). Methods for high-throughput drug combination screening and synergy scoring. In Methods in molecular biology (pp. 351-398). Humana Press Inc.

Hoffmann, M., Kleine-Weber, H., Schroeder, S., Krüger, N., Herrler, T., Erichsen, S., Schiergens, T. S., Herrler, G., Wu, N. H., Nitsche, A., Müller, M. A., Drosten, C., \& Pöhlmann, S. (2020). SARS-CoV-2 cell entry depends on ACE2 and TMPRSS2 and is blocked by a clinically proven protease inhibitor. Cell, 181, 271-280.e8.

lanevski, A., He, L., Aittokallio, T., \& Tang, J. (2017). SynergyFinder: A web application for analyzing drug combination dose-response matrix data. Bioinformatics, 33, 2413-2415. https://doi.org/10.1093/ bioinformatics/btx162 lanevski, A., Yao, R., Fenstad, M. H., Biza, S., Zusinaite, E., Reisberg, T., Lysvand, H., Løseth, K., Landsem, V. M., Malmring, J. F., Oksenych, V., Erlandsen, S. E., Aas, P. A., Hagen, L., Pettersen, C. H., Tenson, T., Afset, J. E., Nordbø, S. A., Bjørås, M., \& Kainov, D. E. (2020). Potential antiviral options against SARS-CoV-2 infection. Viruses, 12, 642. https://doi.org/10.3390/v12060642

Kalil, A. C., Patterson, T. F., Mehta, A. K., Tomashek, K. M., Wolfe, C. R., Ghazaryan, V., Marconi, V. C., Ruiz-Palacios, G. M., Hsieh, L., Kline, S., Tapson, V., lovine, N. M., Jain, M. K., Sweeney, D. A., el Sahly, H. M., Branche, A. R., Regalado Pineda, J., Lye, D. C., Sandkovsky, U., ... Beigel, J. H. (2020). Baricitinib plus remdesivir for hospitalized adults with Covid-19. The New England Journal of Medicine, 384(9), 795-807. https://doi.org/10.1056/NEJMoa2031994

Kim, J. H., Resende, R., Wennekes, T., Chen, H. M., Bance, N., Buchini, S., Watts, A. G., Pilling, P., Streltsov, V. A., Petric, M., Liggins, R., Barrett, S., McKimm-Breschkin, J. L., Niikura, M., \& Withers, S. G. (2013). Mechanism-based covalent neuraminidase inhibitors with broad-spectrum influenza antiviral activity. Science, 340, 71-75.

Kornhuber, J., Tripal, P., Reichel, M., Mühle, C., Rhein, C., Muehlbacher, M., Groemer, T. W., \& Gulbins, E. (2010). Functional inhibitors of acid sphingomyelinase (FIASMAs): A novel pharmacological group of drugs with broad clinical applications. Cellular Physiology and Biochemistry, 26 (1), 9-20.

Kühnl, A., Musiol, A., Heitzig, N., Johnson, D. E., Ehrhardt, C., Grewal, T., Gerke, V., Ludwig, S., \& Rescher, U. (2018). Late endosomal/lysosomal cholesterol accumulation is a host cell-protective mechanism inhibiting endosomal release of influenza A virus. MBio, 9, e01345-e01318.

Lan, J., Ge, J., Yu, J., Shan, S., Zhou, H., Fan, S., Zhang, Q., Shi, X., Wang, Q., Zhang, L., \& Wang, X. (2020). Structure of the SARS-CoV-2 spike receptor-binding domain bound to the ACE2 receptor. Nature, 581, 215-220. https://doi.org/10.1038/s41586-020-2180-5

Lestner, J., \& Hope, W. W. (2013). Itraconazole: An update on pharmacology and clinical use for treatment of invasive and allergic fungal infections. Expert Opinion on Drug Metabolism \& Toxicology, 9, 911-926. https://doi.org/10.1517/17425255.2013.794785

Li, W., Moore, M. J., Vasllieva, N., Sui, J., Wong, S. K., Berne, M. A., Somasundaran, M., Sullivan, J. L., Luzuriaga, K., Greenough, T. C., Choe, H., \& Farzan, M. (2003). Angiotensin-converting enzyme 2 is a functional receptor for the SARS coronavirus. Nature, 426, 450-454. https://doi.org/10.1038/nature02145

Li, Y., Cao, L., Li, G., Cong, F., Li, Y., Sun, J., Luo, Y., Chen, G., Li, G., Wang, P., Xing, F., Ji, Y., Zhao, J., Zhang, Y., Guo, D., \& Zhang, X. (2020). Remdesivir metabolite GS-441524 effectively inhibits SARSCoV-2 infection in mice models. BioRxiv, 2020(10), 353300.

Malyutina, A., Majumder, M. M., Wang, W., Pessia, A., Heckman, C. A., \& Tang, J. (2019). Drug combination sensitivity scoring facilitates the discovery of synergistic and efficacious drug combinations in cancer. PLoS Computational Biology, 15(5), e1006752. https://doi.org/10. 1371/journal.pcbi.1006752

Musiol, A., Gran, S., Ehrhardt, C., Ludwig, S., Grewal, T., Gerke, V., \& Rescher, U. (2013). Annexin A6-balanced late endosomal cholesterol controls influenza a replication and propagation. MBio, 4, 1-11.

Ou, X., Liu, Y., Lei, X., Li, P., Mi, D., Ren, L., Guo, L., Guo, R., Chen, T., Hu, J., Xiang, Z., Mu, Z., Chen, X., Hu, K., Jin, Q., Wang, J., \& Qian, Z. (2020). Characterization of spike glycoprotein of SARS-CoV-2 on virus entry and its immune cross-reactivity with SARS-CoV. Nature Communications, 11, 1-12.

Pope, S., \& Zaraa, S. G. (2016). Serum fluoxetine and norfluoxetine levels support the safety of fluoxetine in overdose. Annals of General Psychiatry, 15, 30-34. https://doi.org/10.1186/s12991-016-0117-z

Preskorn, S. H., Silkey, B., Beber, J., \& Dorey, C. (1991). Antidepressant response and plasma concentrations of fluoxetine. Annals of Clinical Psychiatry, 3, 147-151. https://doi.org/10.3109/ 10401239109147984 
Pruijssers, A. J., George, A. S., Schäfer, A., Leist, S. R., Gralinksi, L. E., Dinnon, K. H., Yount, B. L., Agostini, M. L., Stevens, L. J., Chappell, J. D., Lu, X., Hughes, T. M., Gully, K., Martinez, D. R., Brown, A. J., Graham, R. L., Perry, J. K., Du Pont, V., Pitts, J., Ma, B., Babusis, D., Murakami, E., Feng, J. Y., Bilello, J. P., Porter, D. P., Chilar, T., Baric, R., Denison, M., \& Sheahan, T. P. (2020). Remdesivir inhibits SARS-CoV-2 in human lung cells and chimeric SARS-CoV expressing the SARS-CoV-2 RNA polymerase in mice. Cell Reports, 32, 107940. https://doi.org/10.1016/j.celrep.2020.107940

Pushpakom, S., lorio, F., Eyers, P. A., Escott, K. J., Hopper, S., Wells, A., Doig, A., Guilliams, T., Latimer, J., McNamee, C., Norris, A., Sanseau, P., Cavalla, D., \& Pirmohamed, M. (2018). Drug repurposing: Progress, challenges and recommendations. Nature Reviews. Drug Discovery, 18 41-58.

Rajgor, D. D., Lee, M. H., Archuleta, S., Bagdasarian, N., \& Quek, S. C. (2020). The many estimates of the COVID-19 case fatality rate. The Lancet Infectious Diseases, 20, 776-777. https://doi.org/10.1016/ S1473-3099(20)30244-9

Schloer, S., Brunotte, L., Goretzko, J., Mecate-Zambrano, A., Korthals, N., Gerke, V., Ludwig, S., \& Rescher, U. (2020). Targeting the endolysosomal host-SARS-CoV-2 interface by clinically licensed functional inhibitors of acid sphingomyelinase (FIASMA) including the antidepressant fluoxetine. Emerging Microbes \& Infections, 9, 1-26.

Schloer, S., Goretzko, J., Kühnl, A., Brunotte, L., Ludwig, S., \& Rescher, U. (2019). The clinically licensed antifungal drug itraconazole inhibits influenza virus in vitro and in vivo. Emerg. Microbes Infect., 8, 80-93. https://doi.org/10.1080/22221751.2018.1559709

Schloer, S., Goretzko, J., Pleschka, S., Ludwig, S., \& Rescher, U. (2020). Combinatory treatment with oseltamivir and itraconazole targeting both virus and host factors in influenza a virus infection. Viruses, 12, 703-716. https://doi.org/10.3390/v12070703

Schwegmann, A., \& Brombacher, F. (2008). Host-directed drug targeting of factors hijacked by pathogens. Science Signaling, 1, re8.

Sheahan, T. P., Sims, A. C., Graham, R. L., Menachery, V. D., Gralinski, L. E., Case, J. B., Leist, S. R., Pyrc, K., Feng, J. Y., Trantcheva, I., Bannister, R., Park, Y., Babusis, D., Clarke, M. O., Mackman, R. L., Spahn, J. E., Palmiotti, C. A., Siegel, D., Ray, A. S., ... Baric, R. S. (2017). Broadspectrum antiviral GS-5734 inhibits both epidemic and zoonotic coronaviruses. Science Translational Medicine, 9, eaal3653. https://doi. org/10.1126/scitransImed.aal3653

Sheahan, T. P., Sims, A. C., Leist, S. R., Schäfer, A., Won, J., Brown, A. J., Montgomery, S. A., Hogg, A., Babusis, D., Clarke, M. O., Spahn, J. E., Bauer, L., Sellers, S., Porter, D., Feng, J. Y., Chilar, T., Jordan, R., Densison, M. R., \& Baric, R. S. (2020). Comparative therapeutic efficacy of remdesivir and combination lopinavir, ritonavir, and interferon beta against MERS-CoV. Nature Communications, 11, 1-14.

Shin, J. H., Choi, K. Y., Kim, Y. C., \& Lee, M. G. (2004). Dose-dependent pharmacokinetics of itraconazole after intravenous or oral administration to rats: Intestinal first-pass effect. Antimicrobial Agents and Chemotherapy, 48, 1756-1762. https://doi.org/10.1128/AAC.48.5.17561762.2004

Strasfeld, L., \& Chou, S. (2010). Antiviral drug resistance: Mechanisms and clinical implications. Infectious Disease Clinics of North America, 24, 809-833. https://doi.org/10.1016/j.idc.2010.07.001

Tang, T., Bidon, M., Jaimes, J. A., Whittaker, G. R., \& Daniel, S. (2020). Coronavirus membrane fusion mechanism offers a potential target for antiviral development. Antiviral Research, 178, 104792-104808. https://doi.org/10.1016/j.antiviral.2020.104792

Tempestilli, M., Caputi, P., Avataneo, V., Notari, S., Forini, O., Scorzolini, L., Marchioni, L., Ascoli Bartoli, T., Castilletti, C., Lalle, E., Capobianchi, M. R., Nicastri, E., D'Avolio, A., Ippolito, G., Agrati, C., \& the COVID 19 INMI Study Group. (2020). Pharmacokinetics of remdesivir and GS-441524 in two critically ill patients who recovered from COVID-19. The Journal of Antimicrobial Chemotherapy, 75, 2977-2980. https://doi.org/10.1093/jac/dkaa239

Trinh, M. N., Lu, F., Li, X., Das, A., Liang, Q., De Brabander, J. K., Brown, M. S., \& Goldstein, J. L. (2017). Triazoles inhibit cholesterol export from lysosomes by binding to NPC1. Proceedings of the National Academy of Sciences, 114, 89-94. https://doi.org/10.1073/pnas. 1619571114

Warren, T. K., Jordan, R., Lo, M. K., Ray, A. S., Mackman, R. L., Soloveva, V., Siegel, D., Perron, M., Bannister, R., Hui, H. C., Larson, N., Strickley, R., Wells, J., Stuthman, K. S., van Tongeren, S. A., Garza, N. L., Donnelly, G., Shurtleff, A. C., Retterer, C. J., ... Bavari, S. (2016). Therapeutic efficacy of the small molecule GS-5734 against Ebola virus in rhesus monkeys. Nature, 531, 381-385. https://doi.org/ 10.1038 /nature17180

World Health Organization. (2019). World Health Organization model list of essential medicines (Geneve).

Wu, J. T., Leung, K., Bushman, M., Kishore, N., Niehus, R., de Salazar, P. M., Cowling, B. J., Lipsitch, M., \& Leung, G. M. (2020). Estimating clinical severity of COVID-19 from the transmission dynamics in Wuhan, China. Nature Medicine, 26, 506-510. https://doi.org/10.1038/ s41591-020-0822-7

Zhou, P., Yang, X. L., Wang, X. G., Hu, B., Zhang, L., Zhang, W., Si, H. R., Zhu, Y., Li, B., Huang, C. L., Chen, H. D., Chen, J., Luo, Y., Guo, H., Jiang, R. D., Liu, M. Q., Chen, Y., Shen, X. R., Wang, X., ... Shi, Z. L. (2020). A pneumonia outbreak associated with a new coronavirus of probable bat origin. Nature, 579, 270-273. https://doi.org/10.1038/ s41586-020-2012-7

Zimniak, M., Kirschner, L., Hilpert, H., Seibel, J., \& Bodem, J. (2020). The serotonin reuptake inhibitor fluoxetine inhibits SARS-CoV-2. BioRxiv, 2020, 150490.

Zumla, A., Hui, D. S., Azhar, E. I., Memish, Z. A., \& Maeurer, M. (2020). Reducing mortality from 2019-nCoV: Host-directed therapies should be an option. Lancet, 395, e35-e36. https://doi.org/10.1016/S01406736(20)30305-6

\section{SUPPORTING INFORMATION}

Additional supporting information may be found online in the Supporting Information section at the end of this article.

How to cite this article: Schloer S, Brunotte L, MecateZambrano A, et al. Drug synergy of combinatory treatment with remdesivir and the repurposed drugs fluoxetine and itraconazole effectively impairs SARS-CoV-2 infection in vitro. Br J Pharmacol. 2021;178:2339-2350. https://doi.org/10. 1111/bph.15418 